\title{
O "Galo cantou", mas não foi para os moradores das favelas: problematizando a política estadual de titulação de favelas
}

\author{
Alex Ferreira Magalhães ${ }^{1}$
}

\begin{abstract}
Resumo
O trabalho tem como objetivo debater uma experiência recente, de titulação fundiária de moradores de favelas, apoiada pelo Estado do Rio de Janeiro, mas concebida e executada pela chamada "iniciativa privada". São apresentadas e analisadas, desde uma ótica jurídica e sociopolítica, as principais dimensões dessa experiência, tais como aquelas referentes aos seus agentes promotores, à concepção do papel do Estado e da população beneficiária no desenvolvimento do projeto, ao ideário que a orienta, aos instrumentos jurídicos de titulação que nela são adotados e defendidos, e às transformações mais amplas almejadas para as favelas. A hipótese é a de que se trata de uma proposição que apresenta riscos consideráveis para a população alvo, no tocante ao seu direito à cidade, abrindo-se a possibilidade de que não venha a ser esta a beneficiária final dos investimentos públicos e privados envolvidos no projeto. Tais riscos aumentariam na medida em que o Estado do Rio de Janeiro tem sinalizado que essa experiência passaria a constituir um modelo para as suas futuras intervenções de regularização fundiária.
\end{abstract}

Palavras-chave: Regularização Fundiária. Titulação. Favela(s). (Projeto) Cantagalo. Instituto Atlântico; Estado do Rio de Janeiro.

\begin{abstract}
This work aims to discuss a recent project of slum dwellers land titling, supported by State of Rio de Janeiro, but surprisingly sponsored, conceived and run out by private agents, like businessmen. The main features of that experience are explained and analyzed, from a juridical and socio-political standpoint. For instance, those related to the project's promoters or leaders, to the role of State and of the people seen as the "granted" in its development, to the ideology which guide the project, to the juridical tools which are used and strongly advocated in it, and finally to the wider changes in slums that are looked for. In our first hypothesis, that kind of project brings significant risks to the people who are supposed to be served, regarding to their right to housing and to the city, once they are going to be openly exposed to the market forces. Thus, it makes possible that the ones who are really going to take advantage of the huge public and private efforts involved in the project aren't the traditional slum dwellers, especially the poorest between them. Besides, those risks would

\footnotetext{
${ }^{1}$ Doutor em Planejamento Urbano e Regional - IPPUR/UFRJ, Professor Adjunto da Universidade Federal do Rio de Janeiro. Tem experiência nas áreas de Direito Urbanístico, Regularização Fundiária, Legislação para favelas (estatal e comunitária).
} 
improve and spread given that some State authorities have been announcing this experience as the model to their future projects of slums upgrading and land titling.

Key words: land regularization. land titling. Slums. slum of Cantagalo. Project Cantagalo. Instituto Atlântico. State of Rio de Janeiro.

"O primeiro que tendo cercado um terreno, ousou dizer 'isto é meu' e encontrou pessoas suficientemente simplórias para lhe dar crédito foi o verdadeiro fundador da sociedade civil. Quantos rimes, guerras, assassinatos, quantas misérias e horrores não teria poupado ao gênero humano aquele que, arrancando as estacas ou tampando o fosso, tivesse gritado aos seus semelhantes: 'Evitai escutar esse impostor; estarei perdidos se esquecerdes que os frutos são de todos e a terra não é de ninguém!' Jean-Jacques Rousseau, em Discurso Sobre a Origem e os Fundamentos da Desigualdade Entre os Homens (1750)"

\section{Introdução}

Este trabalho é parte de pesquisa que coordenamos, e que tem por objeto o monitoramento de experiências recentes de regularização fundiária, com especial atenção para aquelas que se encontram em curso na cidade do Rio de Janeiro. Um dos objetivos dessa pesquisa consiste em identificar novas tendências emergentes no seio da política de regularização, debater as metodologias que vêm empregando e analisar os instrumentos jurídicos de que têm se valido.

No presente artigo, focalizaremos uma dessas tendências, representada e/ou protagonizada pelo caso do projeto de titulação, que vem sendo aplicado na favela do Cantagalo, situada entre os bairros de Copacabana e Ipanema, na zona sul da cidade do Rio de Janeiro, região de alta valorização imobiliária, como é de amplo conhecimento, experiência que se anuncia como paradigmática, com vistas à intervenção em favelas, atual e futura, desenvolvida pelo Estado do Rio de Janeiro. Dada a possibilidade de generalização desse modelo, acreditamos que a análise dessa experiência adquire relevância, para o que o presente trabalho deseja trazer, uma contribuição inicial, que venha estimular futuros esforços de conhecimento mais detalhado do mesmo.

Um dos documentos que pode ser tomado como ponto de partida dessa análise consiste na obra intitulada "Galo cantou: a conquista da propriedade pelos moradores do Cantagalo”, lançada em 2011, de autoria de Paulo Rabello de Castro. Tal obra traz um 
amplo e detalhado relato (de 300 páginas), a respeito dos três primeiros anos de desenvolvimento, de um projeto de titulação fundiária dos moradores da favela ali mencionada, relato este da parte de diversos agentes, entre líderes e colaboradores da execução do aludido projeto.

A análise desenvolvida visa identificar e discutir, criticamente, os aspectos que nos parecem constituir as notas essenciais dessa experiência, com vistas a subsidiar prognósticos a respeito de seus impactos atuais e/ou potenciais.

\section{O "Projeto Cantagalo": concepção, referências ideológicas e campo de atores envolvidos}

O projeto de titulação da propriedade fundiária (que alguns preferem denominar formalização da propriedade) da favela do Cantagalo teve início em meados de 2008. Seus autores costumam chamá-lo de Projeto Cantagalo e apresentam-no como um projeto de regularização fundiária. No entanto parece-nos, à primeira vista, que o projeto não se caracteriza como tal, uma vez que não incorpora todas as necessárias dimensões que compõem o conceito contemporâneo de regularização, ${ }^{2}$ concentrando as suas preocupações imediatas com a outorga de títulos sobre os lotes de terra, a fim de que tenham condições de ingressar no chamado fólio real, isto é, nos livros mantidos pelo cartório de registro imobiliário.

Um dos diferenciais do aludido projeto refere-se ao fato de que o mesmo é concebido e coordenado pelo Instituto Atlântico, uma entidade privada, sem fins lucrativos, com sede na Barra da Tijuca (RJ), presidida pelo economista Paulo Rabello de Castro (consultor de empresas e diretor de uma agência de classificação de riscos), constituída desde 1992, com o intuito de "influir no aperfeiçoamento de políticas públicas de forma prática", segundo a forma como se auto-apresenta (http://iatlantico.blogspot.com.br/). Trata-se, portanto, de uma experiência de projeto de titulação, concebida e liderada pela chamada "iniciativa privada", ou por "empreendedores sociais", tal como os autores da proposta se autointitulam, que teriam "o mesmo DNA do empreendedor econômico" (CASTRO, 2011, p.

\footnotetext{
${ }^{2}$ Este conceito tem como referências não somente as obras dos especialistas (por todos, citaria ALFONSIN, 1997), como as publicações técnicas do Ministério das Cidades (BRASIL, 2002), como, por fim, as disposições da Lei Federal no 11.977/2009, especialmente seus artigos 46 a 60.
} 
48).

Os autores apresentam o Projeto Cantagalo como uma parceria entre o asfalto e a favela, como uma posição progressista que defende a causa integracionista da favela. De outro lado, reivindicam para si o comando da ação sobre a favela, não admitindo ficar a reboque dos governos, sendo sua a competência de "sinalizar para onde são necessárias as intervenções do poder público" (CASTRO, 2011, p. 93), o que nos parece, no mínimo, esmaecer o caráter de função pública do urbanismo, um dos princípios gerais do Direito Urbanístico brasileiro, num movimento instituinte, de uma centralidade da iniciativa privada em matéria de políticas urbanas de interesse social. Vem ao encontro disto, a citação que os autores fazem à empresa paranaense Terra Viva, a respeito da qual pairam reservas bastante severas entres os especialistas brasileiros, ${ }^{3}$ como um agente que teria orientação similar.

Um dos aspectos que confere relevância a essa experiência, consiste na intenção que seus autores reiteram em diversos momentos de replicar o projeto, fazendo dele um modelo para a cidade, estado, país e até mundo afora, massificando essa experiência (CASTRO, 2011, p. 88, 163 e 229), a fim de que os moradores de todas as favelas recebam títulos de propriedade de suas casas, nos termos e métodos nela preconizados. Acrescentam, ainda, que buscam a ampliação do Projeto Cantagalo "à quase totalidade das favelas na cidade do Rio e Região Metropolitana até a Olimpíada de 2016”, a fim de que haja resultados "para mostrar ao mundo em 2014, durante a Copa do Mundo que o Brasil sediará" (idem, p. 230), sustentando que essa massificação seria financeiramente viável (idem, p. 233). Conforme demonstraremos ao longo do trabalho, trata-se de uma intenção que não deve ser totalmente subestimada, dado o capital político e econômico de seus defensores, o que levanta riscos consideráveis no tocante à questão do lugar dos pobres nas cidades, dos impactos das políticas de regularização e de seus reais beneficiários.

Para viabilizar a execução do projeto Cantagalo, o Instituto Atlântico arregimentou uma "legião de colaboradores" (CASTRO, 2011, p. 193), tais como moradores, cadastradores, arquitetos, advogados, economistas, engenheiros, servidores públicos, jornalistas, registradores, etc. Articulou o consórcio de uma série de outras instituições, compondo um campo com um perfil estreitamente vinculado ao que, grosso modo, costuma ser designado como poder econômico. A título de exemplo, pode-se citar, entre os principais agentes que se associaram ou são parceiros desse projeto:

\footnotetext{
${ }^{3}$ A exemplo dos participantes da rede intitulada Instituto Brasileiro de Direito Urbanístico (IBDU).
} 
- Aspásia Camargo, deputada estadual pelo PV, além de fundadora e conselheira do Instituto Atlântico;

- dois grandes escritórios de advocacia especializados em questões relacionadas a sociedades empresariais (Direito societário) e mercado de capitais, ambos atuando pro bono, isto é, sem cobrar honorários profissionais;

- uma empresa de assessoria econômica;

- a Escola de Direito da Fundação Getúlio Vargas, filial Rio de Janeiro, que, inclusive, criou uma Clínica de Regularização Fundiária, em 2009;

- dois escritórios de arquitetura e urbanismo;

- Instituto Millenium;

- a FECOMERCIO, que congrega 154 sindicatos patronais do segmento de comércio, serviços e turismo;

- a empresa Localiza, líder do mercado brasileiro de locação de veículos; ${ }^{4}$

- a Associação Nacional dos Cartórios Registradores;

- o ex-governador Moreira Franco;

- as Organizações Globo, de maneira geral, em especial o projeto "Criança esperança", além de alguns dos altos quadros dessas organizações, como João Roberto Marinho, Merval Pereira e Lucia Hipólito;

- Instituto Gerdau;

- uma organização de moradores do bairro de Ipanema, emblematicamente intitulada Projeto de Segurança de Ipanema.

Em que pese esse arco de alianças, o Instituto Atlântico se apresenta como formado por pessoas "sem vínculo partidário ou ideológico", insistindo a todo o momento em sua suposta "neutralidade" política. Um dos colaboradores do Projeto tentou enfrentar a questão do seu significado político, chegando às seguintes conclusões:

Confesso que não perdi tempo com maiores elucubrações sobre se a luta pela propriedade seria algo de 'direita' ou de 'esquerda', ou então de 'centro', 'liberal' ou 'progressista', menos ainda 'reacionário', 'libertário' ou 'comunista'. Concluí por não me importarem os rótulos. Importava a lei.” (CASTRO, 2011, p. 120).

Em suma, a resposta que deu à questão foi abstrair dela e refugiar-se no porto

\footnotetext{
${ }^{4} \mathrm{Cf}$. http://easywork.comunique-se.com.br/arq/94/arq_94_224525.pdf.
} 
seguro da Lei. No entanto, é muito presente no discurso que os autores do Projeto tecem a respeito de si próprios o argumento segundo o qual se veem numa posição progressista, na medida em que se depararam com críticas vindas de setores sociais conservadores, que se opuseram radicalmente ao projeto, para os quais, qualquer medida no sentido de assegurar direitos à população favelada seria vista como ilegítima, preconizando nada muito além de medidas de repressão e as remoções, no feitio do que predominava na década de 1960 (CASTRO, 2011, p. 113).

Os líderes desse projeto falam a todo o momento da "necessidade de levantar-se a bandeira da regularização fundiária" (CASTRO, 2011, p. 88). Com efeito, temos observado que a regularização não constitui uma bandeira exclusiva dos movimentos populares e de moradia, ou do Movimento Nacional de Reforma Urbana, ou, ainda, das forças políticas que se autodefinem como "de esquerda". Num exemplo do que pode ser considerado o embrião do Projeto Cantagalo, o deputado federal Julio Lopes (PP-RJ), em sua campanha eleitoral para reeleição em 2006, tratou amplamente do tema em tela, no horário eleitoral gratuito. Em 2005, ele assumiu, na Câmara dos Deputados, a Presidência da Comissão de Desenvolvimento Urbano, na qual lutou pela realização da regularização fundiária nas favelas do Rio de Janeiro, especialmente na Rocinha e no Vidigal. Sustentou então que "as ideias do poder público e da iniciativa privada precisam ser coordenadas, a fim de proporcionar avanço para a questão da regularização fundiária", lembrando que as empresas privadas estavam fora desse debate, mas que "o apoio financeiro delas é essencial, porque os recursos do governo para a habitação são escassos" ${ }^{5}$, numa linha de argumentação muito próxima àquela mediante a qual se busca justificar a concessão de serviços públicos ao empresariado. Na entrevista que concedeu ao programa televisivo Palavra Aberta, exibido pelo TV Câmara em dezembro de $2005,{ }^{6}$ este parlamentar sustentou vários pontos de vista que vêm totalmente ao encontro de vários dos princípios que orientam o Projeto Cantagalo:

- necessidade de aprovação do PL 3057, em tramitação no Congresso Nacional; ${ }^{7}$

\footnotetext{
${ }^{5}$ Depoimento colhido em http://agenciabrasil.ebc.com.br/noticia/2005-05-12/para-comissao-parcerias-e-planodiretor-sao-fundamentais-na-regularizacao-fundiaria, em 09/11/2012

${ }^{6}$ Esta entrevista pode ser assistida no endereço http://www2.camara.leg.br/tv/materias/PALAVRAABERTA/170198- DEP.-JULIO-LOPES-\%28PP-RJ\%29.html, sendo de se notar que a pauta do próprio entrevistador segue a mesma orientação ideológica.

${ }^{7}$ Projeto que revoga a atual lei de parcelamento do solo urbano (lei 6.766/79), mas que institucionaliza a
} 
- urgência de conter o crescimento das favelas e de incluí-las na legalidade, uma vez que não há legislação específica para esses locais; ${ }^{8}$

- dar aos moradores de favelas, por meio da regularização, o direito de uso de suas habitações e de transmissão de seus imóveis (pressupondo, portanto, que inexistiriam direitos preexistentes à regularização);

- adoção das teses de Hernando de Soto como grande paradigma;

- titulação justificada por permitir a tomada de empréstimo bancário, a fim de transformar barracos de madeira em casas de alvenaria;

- sem a titulação, autoridade que garante a propriedade nas favelas é o tráfico de drogas, estando sob o poder de autoridades fora do controle da legalidade;

- tudo isto seria modificado com a titulação, pois a pessoa passa a poder chamar a polícia e entrar com uma ação de reintegração de posse caso desalojada pelo "chefe do morro";

- $\quad$ sustenta a tese de que "a regularização fundiária é a certidão de nascimento da cidadania".

A filiação explícita e entusiástica ao ideário de Hernando de Soto constitui outra nota essencial da concepção do Projeto Cantagalo, presente desde a dedicatória do livro (ao lado de Steve Jobs, cofundador, presidente e diretor executivo da Apple Inc.), até as frases que epigrafam cada um dos vinte capítulos da obra organizada por Castro, passando por menções diretas por parte do coordenador do Projeto, que parece se apresentar como uma versão tupiniquim do economista peruano (CASTRO, 2011, p.237).

Desse modo, ao longo da obra consultada, reafirmam-se, sem qualquer ressalva, todas as teses desotianas, tais como: criação de riqueza nova por meio da outorga da propriedade plena; acesso ao crédito habitacional mediante o título dominial; propriedade como fator determinante de investimentos em melhorias habitacionais; valorização dos imóveis como efeito direto e imediato da titulação (estimada em aproximadamente $50 \%$ do valor original - vide CASTRO, 2011, p. 234). Em suma, a teoria do capital morto é

figura dos "loteamentos fechados", de interesse de grandes empresas de incorporação imobiliária, a fim de que possam regularizar os vários empreendimentos dessa natureza já edificados no país, criticados por muitos urbanistas por constituir uma forma de constituição de cidades privadas.

${ }^{8} \mathrm{O}$ que, no caso da cidade do Rio de Janeiro, podemos dizer que, em grande medida, é inverídico. 
recepcionada na íntegra, em que pesem as severas reservas que tem recebido, vindas dos insuspeitos quadros da United States Agency for International Development (USAID), que a receberam com grande entusiasmo na década de 1980, no entanto, mais tarde começaram a questionar seus argumentos e a cancelar os financiamentos que concederam a De Soto, chegando, finalmente, à conclusão de que suas proposições representavam uma fraude e que a Agência admitia estar completamente envergonhada de tê-las apoiado por tanto tempo (GILBERT, 2002, p. 3). Trata-se de exemplo que torna ociosa a menção a quaisquer outros, cabendo apenas acrescentar que a adesão a De Soto não deixa de soar como algo extemporâneo, na medida em que tais críticas foram lançadas há mais de dez anos, e têm sido reiteradas desde então. ${ }^{9}$

De modo geral, os líderes do Projeto Cantagalo parecem desconhecer e/ou desconsiderar as amplas críticas já feitas a De Soto, apresentando as suas propostas como revolucionárias. Apresenta-se, ainda, o próprio projeto como "inédito", "inovador", "pioneiro", "participativo", tendo desenvolvido uma singular "tecnologia de mobilização social", ignorando as inúmeras experiências anteriores no continente, que se basearam em idêntica orientação ideológica e que têm sido objeto de severas críticas (ao menos, desde CLICHEVSKY, 2003). Afastada a hipótese de ingenuidade e/ou despreparo dos proponentes do Projeto, sobrariam explicações não muito distantes de uma tentativa assumida de ressuscitar, no campo da política para as favelas, o paradigma geralmente identificado como neoliberal, que predominou no continente latino-americano na década de 1990, que vem sendo seguidamente rechaçado por meio do voto popular na última década. Assim, vale a pena atentar para os fins buscados pelos autores do Projeto, por meio da titulação (CASTRO, 2011, p. 158) e seguintes:

- endereço para cobranças e garantia para empréstimos;

- avaliação de oportunidades por um "grupo maior de pessoas" (o que nos parece uma referência aos agentes externos à favela);

- tornar as pessoas responsáveis e obedientes à lei;

- eliminação do anonimato, do não pagamento de impostos e taxas de fornecimento de serviços (isto é, redução das perdas das concessionárias);

\footnotetext{
${ }^{9}$ Por todos, citaria os trabalhos de Edésio Fernandes (FERNANDES, 2011), uma das maiores autoridade mundiais nos campos do Direito urbanístico e da política urbana.
} 
- eliminação do descumprimento de contratos, pois sem a propriedade escriturada os moradores de favela seriam pessoas que "não teriam nada a perder";

- converter os imóveis em favelas em ativos abstratos, facilitando sua utilização como capital;

- dar mais segurança aos adquirentes de imóveis;

- fornecer informações sobre restrições (ônus reais) que pesam sobre o imóvel;

- converter os moradores em fiscais contra novas ocupações;

- ampliar os estreitos círculos em que são trocadas as propriedades nas favelas (em outras palavras, promover uma grande abertura desse mercado).

A fim de viabilizar o desenvolvimento do Projeto, o Instituto Atlântico se encarregou de captar todos os ultradispendiosos recursos necessários, tais como aqueles para realização de topografia, elaboração de plantas e memorial descritivo da área objeto de titulação (contendo área, medidas perimetrais, coordenada georreferenciadas, confrontantes, etc.), cadastramento físico e socioeconômico, levantamento fundiário, certidões relativas aos imóveis (de ônus reais e do registro de distribuição de ações cíveis), dentre outros.

Contudo, observa-se que ficaram para o poder público as despesas de elaboração e aprovação do projeto de parcelamento do solo (chamado na Prefeitura do Rio de Janeiro de $P A L)$, de registro desse ato e abertura de matrícula de cada imóvel, a fim de que as escrituras de doação possam ser registradas. Muito embora algumas dessas atividades possam ser vistas como atribuições indelegáveis dos órgãos estatais, o dado a ser percebido é o de que o Projeto em questão preocupou-se em captar recursos apenas para a titulação, ficando a cargo do Estado uma série de medidas essenciais dentro da concepção vigente de regularização fundiária integral e sustentável, o que, no caso, em grande parte veio a ocorrer via iniciativas estatais posteriores, como as do PAC e da UPP, cuja relativa sincronia com o Projeto Cantagalo é vista por seus autores como uma "grande coincidência" (CASTRO, 2011, p. 289). De outro lado, a titulação que está sendo efetivada compreende apenas o lote, não a edificação, que pode permanecer na irregularidade, dado que não está sendo providenciada a certidão de Habite-se, bem como as matrículas abertas contemplam apenas o solo, não a edificação (CASTRO, 2011, p. 152 e 200), sem o que estes imóveis constarão no fólio real como terra nua.

De outro lado, o Projeto abrange apenas o Cantagalo, não o Pavão-Pavãozinho, 
favela praticamente geminada com a anterior, cujas histórias se encontram fortemente imbricadas, embora guardem entre si históricos contrastes e tensões, de modo que a primeira parece ter sido, tradicionalmente, um pouco mais bem "aquinhoada" do que a última, o que se revela nos dados disponíveis sobre o IDH e o acesso a serviços urbanos ostentados por cada uma. Segundo os autores do Projeto Cantagalo, tal restrição se deveu à limitação de recursos e não à sua falta de vontade (CASTRO, 2011, p. 197 e 199). Trata-se, portanto, de algumas limitações consideráveis apresentadas por esta experiência de intervenção em favelas.

Segundo o relato dos autores, a execução do projeto é desencadeada a partir de uma assembleia da Associação de Moradores do Cantagalo, por sua vez precedida de uma série de encontros nos quais o mesmo teria sido explicado aos moradores. Como resultado dessa assembleia, os moradores teriam decidido, unanimemente, outorgar mandato aos advogados vinculados ao projeto, a fim de que os mesmos passassem a agir como representantes deles "em Juízo e fora dele" - junto a órgãos como o Governo Estadual, ITERJ, ALERJ, Prefeitura da Cidade, Cartórios, etc. - a fim de que fizessem os agenciamentos políticos necessários à consecução do projeto. Os autores insistem, em vários momentos, que os moradores do Cantagalo aderiram ao projeto de titulação e que o aprovaram incontestavelmente e sem qualquer ressalva. Porém, reconhecem que tiveram de fazer um ingente trabalho de convencimento, envolvendo um sem número de reuniões entre eles e os moradores da favela.

$\mathrm{O}$ caso em questão parece-nos como um daqueles em que se pode afirmar terem sido os assessores técnicos que contrataram seus clientes, e não o oposto, como seria a ordem comum dessa relação. Em que pese a crítica acertada que fazem aos projetos para favelas, concebidos "de fora para dentro" ou "de cima para baixo", a crítica parece se aplicar, em grande medida, a essa mesma experiência. Por exemplo, embora se critique, mais uma vez corretamente, a infantilização do favelado e preconize-se o seu empoderamento, informase que o jornal comunitário do Cantagalo passou a ser sustentado pelo Instituto Atlântico (CASTRO, 2011, p. 65), bem como seu objetivo é definido como o de "conscientizar o leitor" a respeito da necessidade da regularização fundiária, sustentando-se, ainda, que o Projeto é aquele que dá voz aos favelados (idem, p. 300). A concepção de "gestão democrática" adotada pelo Projeto exaure-se na realização de assembleias comunitárias com caráter meramente explicativo do Projeto, nas quais se extraiu o consentimento para início 
dos trabalhos. De outro lado, ressalte-se que os moradores do Cantagalo não participaram diretamente de nenhum dos encontros agendados por seus procuradores junto aos órgãos públicos, não tendo havido presentação dos mesmos, que ficaram excluídos de intervir em negociações fundamentais a respeito de seus próprios destinos. Surpreende-nos que a própria Associação de Moradores não tenha levantado esse questionamento ao longo de todo o processo, deixando de reivindicar para si, de modo indelegável, a representação política e formal dos moradores da favela, como costumamos assistir em diversas oportunidades. Causa-nos espécie, ainda, que os agentes públicos não tenham demandado a presença dos moradores em tais fóruns, a fim de se certificarem da exata correspondência entre os seus interesses e os termos do projeto apresentado por seus procuradores, como nos parece que exigiriam as boas práticas de gestão pública. Tal fato nos conduz ao tópico seguinte de nossa análise dessa experiência.

\section{A relação entre proponentes do projeto e as autoridades públicas}

Ao longo do relato dos autores do Projeto a respeito de sua experiência, determinadas autoridades, como o Governador Sérgio Cabral, seu vice, Luiz Fernando Pezão, além do chefe da Casa Civil Régis Fichtner e o Secretário de Habitação, Leonardo Picciani, são mencionados em diversos momentos, a fim de creditar-lhes o mérito de "adotarem o projeto politicamente e o bancarem contra resistências internas" (CASTRO, 2011, p. 9). Assim, são apresentados como líderes políticos competentes, responsáveis e visionários, que "compreenderam" a proposta de titulação, sendo que o governador é apresentado como líder político, cuja "sensibilidade para o avanço social é notável e persistente" (CASTRO, 2011, p. 229). Em relação a Luiz Fernando Pezão, virtual candidato situacionista à sucessão estadual em 2014, se afirma que "havia no topo da pirâmide política do estado a sensibilidade de um político com vocação para ouvir e agir” (CASTRO, 2011, p. 133).

Tais elogios rasgados vêm em decorrência de o Governo estadual ter viabilizado juridicamente o Projeto, mediante o envio de uma proposta de emenda constitucional (PEC), e de um projeto de lei complementar (PLC) para regulamentá-la, ambos aprovados "em tempo absolutamente recorde" na Assembleia Legislativa Estadual (ALERJ), permitindo que os órgãos estaduais, que detém a propriedade de grande parte da área ocupada pela favela do Cantagalo, fizessem a doação desses imóveis aos seus respectivos ocupantes. Além 
disso, o Estado aprovou a isenção de Imposto de Transmissão de bens imóveis (ITD) para essas doações.

Quanto a estes episódios, vários aspectos chamam atenção do observador. Com efeito, pode-se afirmar ter sido estranhamente incomum a velocidade da aprovação dos dois diplomas legais que dão suporte ao projeto. A PEC no 49/2009, que originou a Emenda Constitucional $n^{\circ}$ 46/2009, foi datada e protocolada em 01/09/2009, vindo a ser aprovada em 30/09, com apenas um voto contrário dos 70 deputados estaduais, sendo promulgada na mesma data, menos de um mês após o início de sua tramitação. Já o PLC no 27/2009, que deu origem à Lei Complementar $n^{\circ} 131 / 2009$, foi datado e protocolado em $12 / 08 / 2009$, aprovado na sessão de $05 / 11 / 2009$, sancionado no dia seguinte, e publicado em 09/11/2009, menos de três meses após a Mensagem do Governador que o remeteu à ALERJ.

De outro lado, a proposta de emenda constitucional foi enviada ao legislativo quase um mês após a remessa do projeto de lei que, em tese, viria para regulamentá-la, invertendo aquilo que seria a ordem natural do processo legiferante, o que sugere que já havia acordo político anterior, com relação ao conteúdo dessa legislação, razão pela qual poucos parlamentares se dispuseram a emendá-la e debatê-la ao longo de sua tramitação na casa legislativa.

Ressalte-se, ainda, que o Estado buscou aprovar essa legislação no intuito de resolver o "problema do Cantagalo", no entanto, nesse caso, os moradores já tinham adquirido anteriormente o direito ao reconhecimento de direitos sobre o solo ocupado, bastando a promoção de ação declaratória da propriedade (por usucapião), para uns, e do processo administrativo, ou ação judicial, declaratórios do direito real de uso para fim de moradia (Concessão de Uso Especial para Moradia - CUEM), para outros. Assim, no caso do Cantagalo, se está doando aquilo que, juridicamente, já pertence aos moradores, fazendo lembrar a célebre sentença de Vinicius de Moraes, em $O$ operário em construção, na qual, diante dos subornos que lhe são oferecidos pelo patrão, ali comparados às tentações que Cristo teria sofrido em seus 40 dias no deserto, o operário retruca, de modo definitivo: “Mentira! Não podes dar-me o que é meu”. Assim, parece-nos que a legislação editada em 2009, que autoriza o Estado do Rio de Janeiro a promover a doação de imóveis públicos em processos de regularização fundiária, pode vir a produzir efeitos que transcendem o caso do Cantagalo, de modo a não só institucionalizar a privatização de reservas fundiárias como diretriz de gestão pública, como, simultaneamente, a hegemonizar o princípio da propriedade 
privada nos assentamentos populares e de baixa renda, agindo no sentido de desconstituir outras situações jurídicas fundiárias, preteritamente formadas em função do tempo e das características da posse. Esse modelo de titulação, nas palavras do próprio vice-governador, que escreve um dos capítulos da obra de autoria de Castro (2011), constituiria o grande legado social do governo chefiado por Sérgio Cabral (idem, p. 127).

Retornaremos ao ponto relativo à propriedade privada na próxima sessão deste trabalho. Antes, cabe assinalar, rapidamente, que outros agentes públicos - que não aqueles acima mencionados, que não são claramente identificados e cujo comportamento não é descrito - são apresentados pelos autores do Projeto Cantagalo, como os seus grandes adversários. As suas críticas mais duras dirigem-se, em especial, à "burocracia intermediária" (CASTRO, 2011, p. 150), aos "políticos populistas" (idem, p. 227), que se autorrotulam de esquerda (idem, p. 64), cujas arcaicas soluções que apresentaram para as favelas jamais funcionaram (idem, p. 31), sendo os responsáveis pelas "barreiras ideológicas, burocráticas, organizacionais e ambientais" (idem, p. 228) que atrasam a regularização fundiária. Registre-se, por fim, que, em que pese o papel crucial desempenhado pelos municípios em qualquer projeto de regularização (dadas as suas competências constitucionais), são muito discretas as menções feitas ao Prefeito Eduardo Paes, ao longo de toda a obra aqui comentada, que não foi convidado - nem qualquer dos integrantes de seu staff político - a escrever nenhum de seus vinte capítulos, restando-lhe um breve depoimento de duas páginas ao final da mesma, numa espécie de anexo dela, não lhe sendo direcionados os generosos elogios dispensados às mais altas autoridades estaduais.

\section{A louvação da propriedade privada: "a propriedade titulada é o maior e mais potente mecanismo de distribuição da riqueza" (CASTRO, 2011, p. 178)}

Toda a concepção do Projeto Cantagalo sustenta-se no pressuposto de que os moradores de favelas dependeriam da obtenção da propriedade dos imóveis onde residem de maneira plena, individual, sem cláusulas restritivas, escriturada e registrada - para alcançarem e exercerem a chamada cidadania. Uma vez obtida esta espécie de propriedade, o resultado fatal e necessário seria a melhoria da inserção social dos favelados e a superação das barreiras que impedem a sua integração. Em suma, a equação proposta pelos autores seria [titulação = integração]. A propriedade levaria, aos moradores de 
favelas, os serviços públicos básicos, bem como lhes daria o direito de exigirem esses serviços (CASTRO, 2011, p. 87 e 92).

A perspectiva dos autores do projeto consiste numa atribuição de qualidades mágicas e/ou excepcionais à instituição da propriedade, apresentadas como largamente aceitas, como verdadeiras entre os especialistas. Recolhemos as seguintes, na obra aqui tomada como referência (CASTRO, 2011):

- garantidora da democracia (p. 134-5), não havendo "democracia sustentável sem amplo acesso de todos ao direito de propriedade" (p. 219);

- assegura as mesmas garantias vigentes para o asfalto, no caso de desapropriações (p. $112)$;

- garantia contra remoções forçadas e do direito à justa indenização em caso de desapropriação (p. 157);

- acaba com o sentimento de insegurança (p. 268);

- $\quad$ assegura inclusão social (p. 269);

- amplia condição de cidadania (p. 269);

- torna o indivíduo comprometido com a manutenção da ordem no entorno de sua propriedade (p. 276);

- cria forte tendência de os moradores investirem mais na melhoria de suas casas (p. $183)$;

- introduz mudanças culturais e de comportamento (p. 277);

- promove um choque de cidadania e salto de riqueza, trazidos pelo registro imobiliário da propriedade (p. 179);

- faz com que o morador seja mais contribuinte e mais demandador de serviços públicos (p. 236);

- permite o voto com maior consciência e liberdade, rompendo a escravidão para com o clientelismo político (p. 236);

- confere autonomia ao morador para decidir sobre o seu destino (p. 286);

- injeta novos valores de comportamento social (p. 290);

- transforma os moradores da favela em cidadãos plenos (p. 290).

Trata-se de argumentos que não somente mitificam a instituição da propriedade privada, como também não encontram correspondência nos dados obtidos em nossas 
pesquisas empíricas realizadas em favelas (MAGALHÃES, 2010). Entre muitos dados que poderíamos invocar para refutar tais afirmações, podemos citar os depoimentos dos próprios agentes municipais, envolvidos nos programas de regularização fundiária e urbanística em favelas, os quais foram categóricos em excluir a ideia de que a titulação importa em integração, o que depende de um conjunto muito maior de fatores. Outra constatação que emerge com força dos dados que produzimos é a de que a tendência de os moradores de favelas investirem mais na melhoria de suas casas depende muito menos da titulação oferecida pelo poder público, e, muito mais de sua percepção de segurança na posse dos imóveis que habitam.

De modo geral, comparece como constante nas colocações dos autores uma conveniente! - confusão entre titulação e segurança da posse, fazendo daquela o grande objetivo das políticas de regularização, bem como um equivalente desta. Tal posição conduz a consideráveis equívocos, quer de ordem técnico-legal, quer de conhecimento das relações sociais, como ocorre na sustentação de que:

A propriedade imobiliária é a melhor resposta às angústias naturais
de um favelado, cuja moradia sem direito constituído não admite
defesa policial ou judicial contra a bandidagem ou a remoção pela
própria administração pública. Essa insegurança se converte em
instabilidade em todos os aspectos da vida, daí a maior propensão
à violência, seja a violência doméstica, especialmente contra
mulheres e crianças, seja a violência armada entre facções
concorrentes contra a população em geral" (CASTRO, 2011, p. 292).

Passa-se, sutilmente, de um debate a respeito do acesso à propriedade, para um debate a respeito do acesso à moradia, um movimento que não poderia passar acriticamente aos olhos de seus autores. Promove-se uma errônea associação (ou identificação) entre titulação como dono e segurança (ou estabilidade) da posse, vendo naquela uma condição não somente necessária, como suficiente, para que se atinja esta. Os riscos citados acima, a toda evidência, não são elimináveis via outorga da propriedade, ou de qualquer outra forma de titulação, diga-se de passagem. Segundo nos parece claro, não há instrumento de titulação ontologicamente bom ou mais perfeito que os demais, ou ainda uma "essência humana da propriedade" como quer Castro (2011, p. 33). Avaliações qualitativas dos mecanismos concretos da titulação dependem sempre de uma análise situacional bastante apurada, bem como do próprio projeto de regularização e de urbanização no qual o instrumento se insere.

No tocante ao tema das ameaças geradas por desapropriações, apresenta-se a propriedade como uma forma de prevenção contra esse risco, olvidando-se, deliberadamente, 
que qualquer propriedade está sujeita a ser desapropriada, bem como que, mesmo localidades que contem com o que os autores chamam de "título definitivo" de propriedade têm enfrentado, o problema das remoções arbitrárias, como noticiado pelo Comitê Popular da Copa e Olimpíadas do Rio de Janeiro (vide COMITÊ, 2012).

De outro lado, a associação feita entre titulação e direito aos serviços públicos promove um considerável retrocesso político e jurídico, na medida em que, já no ano de 1990, a Lei Orgânica do município do Rio de Janeiro havia consagrado, em seu Art. 439, parágrafo único, que “A prestação de serviços públicos à comunidade de baixa renda independerá do reconhecimento de logradouros e da regularização urbanística ou registrária das áreas e de suas construções”. Afirma-se a necessidade do reconhecimento da propriedade antes do reconhecimento de outros direitos civis, humanos e sociais, ou, pior, de modo a colocar estes na dependência daquela.

A posição sustentada pelos autores do Projeto Cantagalo ilustra não somente a magicização da propriedade, como também o que temos chamado de fetiche do registro imobiliário, apresentado como "a única forma de legalmente se adquirir a condição de proprietário no Brasil. (...) Fora do RGI a terra é, no máximo, uma posse. (...) somente pode ser chamado de proprietário aquele que tem seu nome ali inscrito", sem ele o direito formal sobre a terra seria nenhum (CASTRO, 2011, p. 193, 194 e 196). Justifica-se a ênfase na outorga de títulos de propriedade com base numa compreensão determinada de isonomia entre moradores das favelas e do asfalto, no entanto, ignora-se que, neste também, encontram-se propriedades sem matrícula, bem como pessoas que moram de aluguel, ou cuja propriedade consiste, na verdade, em domínio útil (aforamentos), ou funda-se em promessa de compra e venda, em contratos de gaveta, e nem por isto tais indivíduos deixam de exercer plenamente a sua cidadania ou de estarem condenados à insegurança da posse, já tendo tido seus direitos reafirmados na própria jurisprudência do STF.

O dado concreto a ser considerado é o de que o país está longe de constar ou de caber nos livros zelosamente guardados pelos registradores imobiliários, e o de que a sociedade opera e se reproduz apesar desse fato - em alguns casos, poderíamos dizer, de costas para esse fato. Num exemplo extremo, o que seria de determinados países europeus, nos quais se verifica larga predominância da moradia sob locação, a serem consideradas verdadeiras as hipóteses sustentadas pelos patrocinadores do Projeto Cantagalo? 
Outro aspecto perverso a ser comentado é que, em nome da afirmação da propriedade privada, desmoralizam-se as demais formas de titulação que a legislação oferece para o desenvolvimento das políticas de regularização fundiária. Recolhemos, na obra consultada, injustas críticas às instituições da Concessão de Direito Real de Uso (CDRU) e da Concessão de Uso Especial para Moradia (CUEM), apresentadas - do ponto de vista jurídico, erroneamente - como modalidades frágeis, precárias e/ou inadequadas de titulação (CASTRO, 2011, p. 78), não representando solução prática para o problema fundiário (idem, p. 129), crítica que caberia a outros instrumentos - tais como a Permissão de Uso - que não vêm sendo utilizados em projetosde regularização. Tratam-se de equívocos jurídicos tão elementares, que não são explicáveis senão pelo grau de adesão ideológica à instituição da propriedade privada e/ou à convergência do projeto em questão, com interesses específicos dos agentes nele envolvidos ou de outrem.

Muitas das supostas "desvantagens" imputadas aos instrumentos de titulação diversos da propriedade (são temporários e não definitivos; não podem ser cedidos ou exigem consentimento da autoridade para tanto; reduzem a mobilidade; impedem alocação mais eficiente de recursos; exigem que a pessoa permaneça pobre para poder continuar a ser beneficiado por ele) ou não são reais ou nos parecem longe de representarem limitações impostas ao morador da favela, mas sim mecanismos que não os expõem às pressões do mercado, a fim de induzir a que os investimentos públicos em regularização venham a beneficiar, de fato, a população de baixa renda.

Outra dimensão bastante problemática da postura de franca exaltação da propriedade escriturada e registrada, aqui debatida, consiste na deslegitimação das formas de registro e documentação da propriedade de terrenos edificações desenvolvidas pelos moradores das favelas. Os autores do projeto relatam os seus ingentes esforços no sentido de "esclarecer" os moradores de favelas de que tais formas não teriam, supostamente, qualquer valor legal (CASTRO, 2011, p. 34 e 35), de nada valendo para administradores ou juízes, não se constituindo em títulos jurídicos "verdadeiros" (idem, p. 38), ou em "bens fundiários impropriamente adquiridos pelos ocupantes das favelas" (idem, p. 54), mediante um "registro informal em livro da Associação, sem valor legal para efeito de domínio" (idem, p. 56). Afirmam que "tiveram" que reorganizar e modernizar os arquivos da Associação de Moradores, que vinha fazendo o "registro precário" das cessões dos direitos de posse. Entre outros fatores que parecem ter contribuído para essa perspectiva, ou que, no mínimo, 
seriam uma boa ilustração dela, estaria a abordagem criminalizadora dessas práticas, adotada na telenovela "Duas caras" (exibida pela Rede Globo, em horário nobre, entre 2007 e 2008), encarnada na figura do líder comunitário Juvenal Antena (representado por Antonio Fagundes).

Em outras palavras, a versão foi convertida em fato, a vida imitaria a ficção. Ignoram-se, nessa perspectiva, os efeitos sociopolíticos profundamente negativos e antidemocráticos advindos dos projetos que procuraram subjugar, substituir, deslegitimar e/ou dissolver as agências comunitárias, intenção que é assumida na obra dos autores do projeto (CASTRO, 2011, p. 254). O discurso dos moradores tomado pelos autores, e por eles elogiado, como exemplo de fala "consciente" foi apenas e tão somente aquele que afirmava que os moradores não tinham direito algum sobre o local em que residem, ratificando a hipótese do nenhum valor jurídico de suas práticas e instituições (idem, p.117).

Muito embora se encontre um discurso de "valorização" da Associação de Moradores, este nos parece ser estruturado na medida do apoio dado pela direção dessa instituição ao projeto de titulação, o que não impede que, no mesmo projeto, encontrem- se proposições que expropriam a Associação das funções que tem desempenhado historicamente, justificadas em nome da "necessidade" de que a favela se torne um bairro como qualquer outro. Trata-se de um aspecto que revela a face cruel da proposta de "integração" que é sustentada via determinados programas de regularização, que não deixa qualquer outra possibilidade ao desenvolvimento das localidades objeto de intervenções dessa natureza, ponto ao qual retornaremos na seção seguinte.

Por fim, também se sustenta - mais uma vez, erroneamente - que, na ausência de titulação, as posses residenciais nas favelas estariam desprovidas dos atributos de dinamismo econômico, tais como o de ceder a outrem temporariamente, de deixar como herança, de repartir, de alugar ou emprestar, de vender, de comprovar residência (CASTRO, 2011, p. 248 e 276). Ignora-se, aqui, o fato básico da extrema disponibilidade admitida pelas situações possessórias, quer do ponto de vista jurídico, quer do econômico. Ignoram-se, ainda, as sucessivas inovações legislativas, introduzidas nas últimas duas a três décadas, no ordenamento jurídico brasileiro, acompanhadas de alguma jurisprudência e de caudalosa doutrina, todas no sentido de valorizar as situações possessórias e reais, paralelas à propriedade clássica, as quais são deploradas pelos autores do Projeto. Nesse sentido, 
valem, por todas as evidências que se possam invocar, os comandos do art. 48 do Estatuto da Cidade, que determinam aos agentes financeiros aceitarem obrigatoriamente os títulos de CDRU como garantia nas operações de crédito habitacional.

Analisados os argumentos dos autores em seu conjunto, consideramos que constituem uma versão ampliada do problema da desjuridicização das situações jurídicas que envolvem as classes populares, que temos diagnosticado (e até mesmo denunciado) desde as primeiras etapas de nossa pesquisa em favelas. Nela desenvolvemos pormenorizada análise da documentação, comumente utilizada para compra e venda de imóveis em favelas, procurando demonstrar a sua validade, quer da perspectiva da ordem jurídica estatal, quer da sensibilidade jurídica e do conceito de Direito desenvolvidos no seio social. Por estas razões, vem sendo utilizada como base de processos de regularização fundiária desenvolvidos na cidade do Rio de Janeiro, bem como no próprio âmbito da Defensoria Pública, em atos de partilha realizados em processos de divórcio ou de sucessão hereditária (MAGALHÃES, 2010).

No fundo, os moradores de favelas não compartilham da visão desjuridicizante aqui criticada, a exemplo do depoimento de um dos líderes entrevistados, para quem o título de propriedade "é mais um documento que teremos em nossa mão para uso de qualquer coisa no futuro" (CASTRO, 2011, p. 265), dando a entender que não descarta outras formas de titulação e formalização da propriedade, como aquela produzida nas práticas jurídicas dos moradores de favelas. A carência destes é a de dispor de "um documento que vai valer na sociedade" e que afaste o estigma da ilegalidade que pesa sobre eles, o que não equivale a um pleito pela titulação como proprietário burguês, a não ser por meio de uma interpretação bastante enviesada.

No âmbito do Projeto Cantagalo define-se o sonho do morador de favelas, como o sonho de ser proprietário, o que estaria no topo de seus sonhos (CASTRO, 2011, p. 61 e 231), fazendo lembrar o "sonho da casa própria", inculcado por Roberto Campos durante o regime militar, como se sabe, menos em função de qualquer perspectiva emancipatória das classes populares e mais como estratégia de ordem, de controle social e de contrarrestar qualquer sedução que o sistema socialista pudesse eventualmente exercer sobre as classes populares. Tal definição contrasta com o clamor por uma "leitura correta do sonho do cidadão da favela" (CASTRO, 2011, p. 179), vindo de encontro ao que tem sido constatado em pesquisas já realizadas, que buscaram elaborar uma escala de demandas prioritárias dos 
moradores de favelas, nas quais a titulação da propriedade jamais aparece nas posições mais altas, gerando certo debate acadêmico a respeito da impopularidade da regularização fundiária (LEITÃO, 2009). Diante desses elementos, caberia indagar de quem, na verdade, seria o sonho aos quais os autores do Projeto aludem. A julgar pelos termos do enfático libelo de defesa da propriedade privada, estampado na obra em análise, não deveria ser descartada a hipótese de que são os autores desta, mais do que os próprios moradores do Cantagalo, que o acalentam.

Os autores do projeto sustentam que o traço distintivo do mesmo consistiria na outorga da propriedade plena, ao invés de simples direitos reais sobre coisa alheia ou do mero reconhecimento de situações possessórias (CASTRO, 2011, p. 153). No entanto, de fato, o distintivo real não nos parece ser este, já que outras experiências, dentro e fora do Brasil, optaram por esse mesmo instrumento. Em nosso ver, o diferencial residiria, antes, no exclusivismo e na ênfase acentuada na propriedade plena, tratada como a única alternativa adequada para a titulação, mesmo em casos, como o do Cantagalo, em que parte dos moradores já adquiriu outros direitos reais, por força do tempo aliado ao cumprimento dos demais requisitos legais.

Apresenta-se o projeto como de acesso à propriedade, porém parece-nos que o que está em jogo é, antes, a transformação da propriedade imobiliária nas favelas, que estaria sendo submetida a um estatuto diferenciado daquele em que tradicionalmente se encontrava. Propõe-se uma determinada modalidade de titulação sem explicitar e considerar os seus custos diretos e indiretos para os moradores, pondo grande ênfase no discurso de que "os deveres acompanham os direitos", sem apurar se tais custos seriam suportáveis, considerada a renda percebida pelos "beneficiários" da titulação, e sem debater as necessárias políticas de tarifação diferenciada, pelos serviços públicos, que, por sinal, é uma exigência contida no próprio Estatuto da Cidade (art. 47), o que permite afirmar que representa um direito subjetivo público da população de baixa renda. O discurso dos autores, portanto, simplifica a complexidade do processo que se encontra em curso, o que dificulta o debate mais aprofundado a respeito do caráter e da legitimidade da mudança que encontra-se em curso. 


\section{Titulação, integração e/ou remoção: qual o futuro da favela?}

Muito embora os autores do Projeto Cantagalo não proponham as remoções a la década de 1960 como política geral para as favelas, curiosamente apresentam-se como tributários daqueles que buscaram erradicá-las (CASTRO, 2011, p. 27), o que nos induz à hipótese de que, de modo um tanto paradoxal, pode-se estar buscando as remoções pela via da titulação, isto é, pelo caminho das forças de mercado, como forma de legitimar esse processo. Desse modo, fugir-se-ia das reações, dos escândalos políticos e das chagas sociais e urbanas deixadas pelas formas mais rudimentares, grosseiras e truculentas de sua realização. Com base em diversos fragmentos da obra consultada (CASTRO, 2011, p. 108109), podemos afirmar que a condenação das remoções é feita, basicamente, para efeito de justificar e legitimar a titulação nos termos propostos, ou seja, não pelas mesmas razões pelas quais os atingidos por estas remoções costumam condená-las, arguindo, por exemplo, o direito dos pobres às áreas centrais das cidades, tal como reivindicado pelos movimentos de moradia. $^{10}$ Nesse sentido, registramos que, embora defendam a doação, os autores consideram que tal medida possuiria evidente cunho populista (CASTRO, 2011, p. 130).

Há, no entanto, evidências mais fortes em prol dessa hipótese. Em capítulo da obra assinado por representante das Organizações Globo, este afirma que, em tese, o melhor dos mundos seria a remoção, porém, pragmaticamente, era obrigado a admitir que isto consistiria em um milagre e que melhor seria buscar um outro caminho para lidar com o problema da favela, caminho este que estava sendo indicado pelo Projeto Cantagalo e que encontrariase-ia "totalmente identificado com os princípios e valores das Organizações Globo" (CASTRO, 2011, p. 167).

Subjazem ao Projeto, os fantasmas da "explosão da favela" e de seu crescimento populacional e físico-espacial, infalivelmente alcunhado de "desordenado". Reclama-se da ausência de políticas públicas de controle e fiscalização das favelas, o que teria deixado a cidade do Rio de Janeiro próxima do colapso urbano e social (CASTRO, 2011, p. 74). A regularização, tanto aqui, quanto no já citado depoimento do deputado Julio Lopes, seria o remédio para corrigir esse mal (idem, p. 88). Assim, o crescimento das favelas é creditado à ausência de regularização fundiária, que evitaria ocupações irregulares (idem, p. 127),

\footnotetext{
${ }^{10}$ A título de exemplo, vide o contido no sítio http://direitoamoradia.org/?p=17617\&lang=en.
} 
retomando-se a avaliação do mainstream, segundo a qual o programa Favela-Bairro teria fracassado por não ter tido êxito em paralisar o crescimento das favelas. Nesse sentido, durante a execução dos trabalhos de titulação, os autores do Projeto promoveram o congelamento urbanístico da favela, orientando os moradores de que seria inadequado fazer qualquer ampliação, restringindo-se as obras à manutenção das edificações existentes (idem, p. 118), restrição que, posteriormente, veio a se consagrar na normatização do uso e ocupação do solo na favela do Cantagalo, editada por meio do Decreto n. ${ }^{\circ} 33015$, de 5/11/2010, do Prefeito do Rio de Janeiro.

De modo geral, os autores posicionam-se contra as políticas tradicionais de remoção (CASTRO, 2011, p. 162-3), porém não tocam no caso daquelas que ocorrem pelas forças do mercado. Não se encontra nenhuma palavra sobre expulsão branca, elitização e/ou gentrificação, como se tais ameaças não se colocassem, não atentando para o depoimento das lideranças comunitárias, que alertam para o fato de que "tá todo mundo querendo subir o morro agora; todo mundo querendo ir pra comunidade agora" (idem, p.264). Na única alusão - não muito direta! - a este problema, que recolhemos nas 300 páginas da obra (idem, p. 253), não se veem esses problemas, como devendo ser enfrentados pelo Projeto Cantagalo e seus empreendedores sociais, sendo vistos, antes, como mais um daqueles que seriam de responsabilidade exclusivamente estatal. Ao longo de toda obra, referem-se a um medo da titulação, que supostamente seria infundado, e que alguns - não claramente identificados - supostamente teriam. No entanto, não se enfrenta o debate a respeito das razões de tais temores, sendo totalmente inócua a mera exortação a sua superação.

Ao conjecturarem sobre o expressivo acréscimo de riqueza, que asseguram que a titulação provocará, parece-nos que a sugestão (e/ou "deixa") implicitamente feita pelos autores do projeto é a de que os moradores das favelas provavelmente realizariam essa valorização mediante a venda de seus imóveis, o que consagraria a sua expulsão pelas forças do mercado, bem como que os segmentos economicamente mais fortes, prováveis adquirentes desses imóveis, seriam os grandes beneficiados pelos (caríssimos!) investimentos públicos (nesse caso, públicos e privados) de regularização. Para onde esses moradores iriam, após a venda de seus imóveis, e quais as implicações desta mobilidade em termos de acesso à cidade, seria, pelo visto na obra em análise, "um outro departamento".

Ao longo da obra vai ficando patenteado que a grande questão dos autores não é a de 
ter melhores cidades e/ou melhores locais para se viver, mas sim lograr um "choque de riqueza", numa variante urbana do quem vem sendo chamado "desenvolvimentismo predatório". Fica nítida a visão das favelas como a nova fronteira de expansão dos circuitos centrais do capitalismo contemporâneo, hipótese que sustentamos anteriormente (MAGALHÃES, 2008). O desejo parece ser o de, fundamentalmente, ampliar as relações capitalistas e de salvá-las, e não o de transformá-las, socializá-las ou humanizá-las. Busca-se fornecer provas de que a ordem capitalista seria sustentável e que seria capaz de dar resposta à questão social. Os pobres não estariam conquistando o direito à cidade de que fala o Estatuto da Cidade, mas sim o direito de se tornarem agentes capitalistas (CASTRO, 2011, p. 235). O que se quer com a titulação é promover acréscimos de valor imobiliário, criar riqueza nova ao mesmo tempo para os dois lados da cidade - favela e asfalto - numa operação do tipo win-win, em que ocorra substantiva adição de valor de riqueza econômica (idem, p. 172, 173 e 178). O grande desafio do Projeto, nessa linha de raciocínio, seria o de convencer os moradores a respeito da proposta de acumulação de riqueza imobiliária, daí terem os seus executores se defrontado, em campo, com o sentimento de desconfiança da parte daqueles, relatando as dificuldades que tiveram em superá-lo (idem, p. 179).

Nesse sentido, parecem-nos claros os débitos do Projeto Cantagalo com concepções bastante reducionistas de cidadania, como aquelas identificam o cidadão ao consumidor (CASTRO, 2011, p. 242). De outro lado, comete-se o equívoco de supor que a valorização imobiliária se traduziria em aumento do poder de compra e da capacidade contributiva dos moradores de favelas (idem, p. 237). Por fim, acena-se aos moradores de favelas com uma valorização que nem mesmo pode-se considerar como certa ou mesmo como resultado atribuível à titulação, construindo-se para ela uma imagem que "pegaria carona" nos efeitos de iniciativas do Estado, e não do Projeto Cantagalo, como os investimentos em urbanização e a política chamada de pacificação.

Por fim, registre-se a colocação - muito repetida na obra em questão e no debate público a respeito do desenvolvimento das favelas - segundo a qual "a favela se encontra numa transição para a formalidade" (CASTRO, 2011, p. 57). Assim, as favelas devem "virar" parte da cidade formal (idem, p. 87), são aquelas que se integram a esta, jamais o contrário, de modo que daquela, a rigor, pouco se aproveita e esta permanece inquestionada em suas dinâmicas excludentes, deixando pouca margem para um processo real "de mão dupla". Em que pesem algumas colocações que parecem atenuar essa 
perspectiva, de modo geral prevalece, na concepção do Projeto Cantagalo, essa abordagem de cunho etnocêntrico, como se percebe no seguinte excerto:

Quando a favela engole a cidade tratar-se-ia de uma forma anômala de integração, pelo rebaixamento do valor médio da riqueza dos dois lados da equação, com a favela provavelmente ganhando muito pouco e o asfalto perdendo muito. Isto é o que vinha acontecendo no Rio de Janeiro, que passou a absorver as normas precárias da contravenção como 'princípio geral de direito', inclusive na vida do carioca do asfalto. A integração por assim dizer positiva, com evidente e substantiva adição de valor de riqueza econômica e juspolítica para todos, é aquela em que o asfalto, gradual e sustentavelmente, se impõe como modelo, pela adoção, na favela, das normas superiores que a cidade formal pratica em sua organização jurídica e social. (...) nada se deve impor, tudo se conversa e negocia e tudo de aprende ou reaprende, sempre com olhos pregados nos objetivos previamente traçados, para que nenhuma concessão, de parte a parte, implique desvio empobrecedor da meta mais alta da integração final e absoluta da cidade da chegada à cidade formal. (CASTRO, 2011, p.173).

Um dos maiores símbolos do modelo de integração sustentado pelo Projeto Cantagalo consiste na construção de uma nova sede da Associação de Moradores, projetada por um dos arquitetos vinculados ao Instituto Atlântico, que, inclusive, abrigará também a sede do POUSO (Posto de Orientação Urbanística e Social, órgão descentralizado da Secretaria de Urbanismo), o que é visto como "coroamento do processo de integração da comunidade à cidade formal, materializando o sonho dos moradores do Cantagalo a um estágio superior de organização social e política (...) símbolo da nova governança local, representando a legitimação política da nova ordem social no Cantagalo" (CASTRO, 2011, p. 290).

Nessa perspectiva, o destino da favela já está previamente dado, indicando-se que não será aceita uma transição para algo diferente daquilo já definido como expectativa ou como evolução desejada dessas regiões.

\section{Considerações finais}

Até o ano de 2011, em termos de titulação, o resultado concreto do Projeto Cantagalo consistia na emissão e entrega de 44 escrituras de doação, em um universo de 1.485 unidades habitacionais existentes no Cantagalo, o que equivale a 3\% delas. Em fins de 2012, anunciou-se a entrega "de 10 mil títulos de posse e propriedade a moradores de baixa 
renda", por parte da Secretaria Estadual de Habitação, em ato realizado no próprio Cantagalo, fato ainda dependente de apuração mais exata, que transcenda o exposto na cobertura do fato pela imprensa oficial, com base numa avaliação de conteúdo dos documentos entregues nessa oportunidade. ${ }^{11}$

Tais escrituras ainda não se encontram registradas, pois, segundo os autores, ainda não foi definido quem arcará com os emolumentos exigidos pelo cartório do registro imobiliário (CASTRO, 2011, p. 151), em que pese o fato de a legislação nacional e estadual assegurar, de longa data, a isenção de tais despesas, especialmente em políticas de interesse social. Ou seja, há resistências e o "consenso" alardeado pelos autores vai se revelando não ser tão amplo e sólido quanto o anunciado.

A experiência do Cantagalo suscita várias questões, que merecem ser objeto de pesquisa, a fim de que se possa gerar um conhecimento dela que ultrapasse os termos do relato dos autores e patrocinadores da proposta de titulação, revelando as perspectivas dos demais agentes envolvidos e interessados nos destinos dessa favela e de outras que se encontrem em situação análoga.

Como demonstrado, trata-se de uma experiência que tem como uma de suas notas a articulação de interesses de agentes externos à favela, como o eixo aglutinador do projeto de titulação. O poder público, nesse caso, vem a reboque das iniciativas e ações dos "agentes promotores" do projeto, constituindo um dos "parceiros" que são atraídos para a sua execução. Não obstante, tal como em outras experiências em que agentes privados desejam chamar a si a execução de políticas ou serviços públicos, o setor privado não absorve todos os custos e ações inerentes à empreitada, socializando uma série deles, a despeito, em muitos casos, dos dividendos de diversas ordens proporcionados pelas mesmas.

O capital econômico dos autores da ideia não se apresenta desacompanhado de capital político, uma vez que lograram acesso às mais altas esferas da administração estadual, que foram, de modo que, para nós, não se encontra inteiramente claro, convencidas a encampar a proposta, o que se materializou na remessa a ALERJ, pelo Governador do Estado, das duas propostas legislativas comentadas no artigo. As hipóteses dos autores, que evocam a "sensibilidade" e espírito público das autoridades estaduais, como justificativa para a incorporação do modelo de titulação, encabeçado pelo Instituto Atlântico, ficam longe de serem aceitáveis, representando um discurso, cuja aparente ingenuidade somente faz

\footnotetext{
${ }^{11}$ Por exemplo, aquela disponível em http://www.rj.gov.br/web/seh/exibeconteudo?article-id=1378919.
} 
aumentar as suspeitas que pairam sobre o Projeto em análise.

Outra particularidade analisada consiste na ênfase - acentuadíssima! - na realização da titulação dos moradores, por meio da outorga da propriedade individual e plena dos imóveis em que residem, feita a título gratuito, isto é, por meio de doação, sem qualquer tipo de restrição à disponibilidade da propriedade, dos próprios estaduais existentes na favela, que constituem a maior parcela do solo ocupado por ela. Além de uma candente defesa da propriedade privada, tomada pelos autores do projeto como passaporte único e seguro para a condição de cidadania, articula-se, em seu discurso, uma deslegitimação aberta das outras possibilidades de titulação, oferecidas pela legislação, que são apresentadas como modos "precários" de se promover a regularização fundiária, adotando entendimento que, juridicamente, nos parece bastante discutível, sem falar na crítica que se pode fazer desde uma perspectiva sociopolítica. De modo geral, no entanto, faltam evidências que deem suporte às proclamadas virtudes que os autores imputam a essa instituição.

Dado o conjunto de objetivos adotados no Projeto em questão, configura-se um verdadeiro projeto de uma "nova favela", que provavelmente não manterá a característica de bairro popular situado em área urbana central, válida para um bom número daquelas situadas nas áreas nobres da cidade do Rio de Janeiro (basicamente as situadas na Área de Planejamento 2, do Plano Diretor do Município do Rio de Janeiro), levantando sérias preocupações, quanto à ordem urbana que emergiria de uma eventual disseminação de tal espécie de projeto urbano. Por mais que não se possuam evidências a respeito de eventuais vínculos não declarados entre os autores do Projeto e grandes agentes do mercado imobiliário e empresarial, a convergência de interesses parece-nos real, e tal hipótese se vê reforçada pelo quadro de agentes do Projeto, pela metodologia e instrumentos de titulação que preconiza e por seus referenciais ideológicos.

Em suma, trata-se de uma proposição que, em quase todos os seus aspectos, apresenta riscos consideráveis para a população que, em princípio, seria a "beneficiária" da ação de titulação, o que representa algo absolutamente contraditório em se tratando de políticas voltadas aos segmentos de baixa renda. Consideradas em seu conjunto, as transformações que os autores propõem para as favelas implicam na expropriação das instituições e dos símbolos elaborados por seus moradores e agentes internos, como se pode observar nos diversos mecanismos de destituição dos papéis e funções exercidos pela Associação de Moradores, numa espécie de rendição ou capitulação diante das forças do "asfalto". Nesse 
sentido, vale recuperar a feliz percepção de um dos agentes municipais atuantes nos POUSOs (registrada em MAGALHÃES, 2010), segundo o qual qualquer processo de regularização, cujas regras sejam muito estreitas, degringolará em remoção, produzindo efeitos práticos muito semelhantes a esta, embora não seja nominalmente classificado como tal, o que aumenta o seu grau de perversidade, na medida em que dificulta o seu reconhecimento e crítica política e analítica. Nesse sentido, podemos afirmar que uma das possibilidades oferecidas pela atual conjuntura é a de que as políticas remocionistas apresentem-se, ardilosamente, travestidas sob o verniz da política de regularização, ou, em outras palavras, chama-se de regularização o que em verdade representa o seu oposto, como estratégia, mais ou menos consciente, de legitimação de uma ação que, de outro modo, enfrentaria resistências insuperáveis, inclusive de ordem legal. Numa outra possível síntese, trata-se, agora, de promover a remoção por meio da (assim chamada!) regularização. Eis a grande ameaça trazida pela experiência aqui analisada.

Esses riscos aumentam na medida em que o Estado do Rio de Janeiro tem sinalizado que essa experiência passaria a constituir um modelo para as suas futuras intervenções em favelas. Isto abre a possibilidade de que tal influência se faça sentir, não somente no município do Rio de Janeiro como em muitos outros, independente do fato de as respectivas administrações estarem politicamente vinculadas à estadual, dado o papel importante de difusão de modelos, de coordenação e de financiamento que a esfera estadual da administração pública pode exercer.

Em suma, a análise dessa experiência chama atenção para o fato de que a regularização fundiária constitui uma política reclamada por segmentos bastante diferenciados do espectro político e social, logo há sempre que se investigar que concepções de regularização subjazem a tais reivindicações, desnaturalizando a enganosa imagem de unidade oferecida por uma nomenclatura comum. No caso específico do Projeto Cantagalo, a análise demonstra tratar-se de uma proposta de titulação - aquém, portanto, de representar uma de regularização - bem como de uma proposta encabeçada e articulada por segmentos, econômica e politicamente poderosos, que nela se engajarem militantemente. Grosso modo, diríamos que o caso estudado demonstra que "a direita" também luta e também ergue bandeiras políticas e ideológicas, ilustrando os recursos (de toda ordem) com os quais essa luta se desenvolve.

A descaracterização da favela mediante a sua desabrida elitização eliminaria parte da 
diversidade socioeconômica e cultural, que nos parece constituir um dos componentes mais ricos e essencialmente democráticos que a cidade do Rio de Janeiro permitiu-se, historicamente. Diante disso, vale o profético alerta de Paulo César Pinheiro, em seu já clássico samba Nomes de favela:

O galo já não canta mais no Cantagalo

A água já não corre mais na Cachoeirinha

Menino não pega mais manga na Mangueira

E agora que cidade grande é a Rocinha!

Ninguém faz mais jura de amor no juramento

Ninguém vai-se embora do morro do Adeus

Prazer se acabou lá no Morro dos Prazeres

E a vida é um inferno na Cidade de Deus

Pela poesia dos nomes de favela

A vida por lá já foi mais bela

Já foi bem melhor de se morar

Mas hoje essa mesma poesia pede ajuda

Ou lá na favela a vida muda

Ou todos os nomes vão mudar

\section{Referências Bibliográficas:}

ALFONSIN, Betânia de Moraes. Direito à moradia: instrumentos e experiências de regularização fundiária nas cidades brasileiras. Rio de Janeiro: FASE, 1997. 248p.

BRASIL, Ministério das Cidades. Regularização da terra e da moradia: o que é e como implementar. Brasília: Ministério das Cidades, 2002. 175p. Disponível em: http://www.cidades.gov.br/images/stories/ArquivosSNPU/Biblioteca/RegularizacaoF undiaria/Regularizacao_Terra_Moradia_Implementar.pdf.

CASTRO, Paulo Rabello de. Galo cantou: a conquista da propriedade pelos moradores do Cantagalo. Rio de Janeiro: Record, 2011. 
CLICHEVSKY, Nora. Pobreza y acceso al suelo urbano: algunas interrogantes sobre las políticas de regularización en América Latina. Santiago de Chile: Nações Unidas / CEPAL / División de Desarrollo Sustenible y Asentamientos Humanos, 2003.

COMITE POPULAR DA COPAE OLIMPÍADAS DO RIODE JANEIRO. Megaeventos e violações dos direitos humanos no Rio de Janeiro: dossiê do Comitê Popular da Copa e Olimpíadas do Rio de Janeiro. Rio de Janeiro: IPPUR, 2012. FERNANDES, Edésio. Regularization of Informal Settlements in Latin America. Cambridge, MA, Lincoln Institute of Land Policy, 2011.Disponível em: http://www.lincolninst.edu/pubs/1906_Regularization-of-Informal-Settlements-in- $\quad$ LatinAmerica.

GILBERT, Alan. On the Mystery of Capital and the myths of Hernando de Soto: what difference does legal title make? International Development Planning Review, Liverpool, v. 24, n. 1, February, 2002, p. 1-19.

LEITÃO, Gerônimo. Dos barracos de madeira aos prédios de quitinetes: uma análise do processo de produção da moradia na Favela da Rocinha, ao longo de cinquenta anos. Niterói: UFF, 2009. 197 p. Tese de Doutorado.

MAGALHÃES, Alex Ferreira. É possível equacionar o problema da pobreza via economia de mercado? A política de formalização da propriedade imobiliária em Hernando De Soto. Cadernos PUR/UFRJ, v. XXI, p. 99-130, 2008.

. O direito da favela no contexto pós-programa Favela-Bairro: uma recolocação do debate a respeito do "Direito de Pasárgada". Tese (doutorado) - Universidade Federal do Rio de Janeiro, Instituto de Pesquisa e Planejamento Urbano e Regional. Rio de Janeiro: UFRJ, 2010. 